\title{
A AQUISIÇÃO DE TERRAS POR ESTRANGEIROS E SOBERANIA: APORTES PARA UMA PROTEÇÃO NORMATIVA
}

\section{THE ACQUISITION OF LANDS BY FOREIGNERS AND SOVEREIGNTY: CONTRIBUTIONS TO NORMATIVE PROTECTION}

\author{
Leila Maria da Juda Bijos ${ }^{1}$ \\ Cristiano de Castro Dayrell ${ }^{2}$
}

\section{Resumo}

O presente artigo trata dos problemas relacionados à aquisição de terras por estrangeiros e a necessidade de impor limites a essa prática em função do disposto no art. 190 da Constituição. Serão analisados os requisitos previstos pela lei no 5.709/71 para aquisição de imóveis rurais por estrangeiros e a importância dos cartórios de registro de imóveis para o controle prévio dessas aquisições. São tratados, também, os limites territoriais dentro de cada município em que estrangeiros podem adquirir terras. Por último, é demonstrado que as tradings internacionais vêm dominando a produção de grãos no Brasil, através de contratos com produtores rurais, garantidos por cédulas de produto rural. Esse controle caracteriza-se como uma forma disfarçada de land grabbing ou concentração de terras por parte de corporações, fundos de investimentos e os mercados financeiros, que se apropriam de extensas glebas de terra, para projetos em larga escala. Como possíveis resultados, destaca-se o controle dessas cédulas através dos cartórios de imóveis brasileiros, que são uma grande ferramenta para a sua efetivação. Trata-se de um estudo descritivo-analítico desenvolvido através de pesquisa bibliográfica, que se enquadra nos campos de Direito e Desenvolvimento, assim como no Direito e Economia.

Palavras-Chave: Aquisição de Terras no Brasil; Registro de Imóveis por Estrangeiros; Soberania Nacional; Desigualdade Social.

\begin{abstract}
This article deals with the problems related to the acquisition of land by foreigners and the need to impose limits to this practice in function of the provisions of art. 190 of the Constitution. It will analyze the requirements imposed by law No. 5.709 / 71 for the acquisition of rural properties by foreigners and the importance of real estate registration offices for the prior control of these acquisitions. The territorial limits within each municipality in which foreigners can acquire land are also treated. Finally, it is demonstrated that international tradings have been dominating grain production in Brazil, through contracts with rural producers, guaranteed by rural product certificates. This control is characterized as a disguised form of land grabbing, which means concentration of land by corporations, investment funds and financial markets, which take over huge land holdings for large-scale projects. As possible results, emphasis is put on the control of these notes, Brazilian real estate registries will be a great tool for their

\footnotetext{
${ }^{1}$ Pos-Doutora pela Saint Mary's University, Halifax, Nova Scotia, Canada. Professor Adjunto do Mestrado em Direito Econômico Internacional da Universidade Católica de Brasília. Coordenadora do Grupo de Pesquisa "Laboratório de Política Internacional", e da Linha de Pesquisa em Direitos Humanos. Membro da Cátedra da UNESCO de Juventude, Educação e Sociedade. Pesquisadora Visitante da Universidade de Hyderabad, Índia; do Programa de Doutorado em Economia Internacional da Universidade de Tsukuba, e da University of Califórnia, San Diego (UCSD). E-mail: leilabijos@gmail.com

${ }^{2}$ Mestrando em Direito na Universidade Católica de Brasília. E-mail: cdayrell@terra.com.br
} 
effectiveness. This is a descriptive-analytical study developed through bibliographical research, which falls within the fields of Law and Development, as well as Law and Economics.

Keywords: Rural Land Acquisition in Brazil; Land Registry by Foreigners; National Sovereignty; Social Inequality.

\section{INTRODUÇÃO}

Os problemas decorrentes do acesso de pessoas estrangeiras às terras brasileiras, evidenciam confrontos rurais, violação de direitos humanos, em face do recorrente movimento mundial de aquisição de terras por empresas multinacionais, especialmente, na América Latina e na África, denominado de land grabbing ou concentração de terras por parte de corporações, fundos de investimentos e os mercados financeiros, que se apropriam de extensas glebas de terra, para projetos em larga escala (SAUER, 2010). Para que se evitem confrontos com os trabalhadores rurais, faz-se mister o controle dessas cédulas através dos cartórios de imóveis brasileiros, que são uma relevante ferramenta para a sua efetivação. A compra de terras por investidores estrangeiros gera dois problemas: o primeiro relacionado à soberania do país, e o segundo diz respeito ao aumento da desigualdade social, por limitar o acesso de produtores nacionais aos imóveis rurais.

Os problemas apontados evidenciam a necessidade de regular e limitar a aquisição e o arrendamento de terras por estrangeiros, em razão de norma constitucional expressa nesse sentido (art. 190 da Constituição). Avaliam-se, os limites e requisitos para a aquisição de terras por estrangeiros, pessoas físicas e jurídicas, e a relevância dos cartórios de registro de imóveis para o efetivo controle pelo Estado dessas aquisições.

Os registros imobiliários, os aspectos notariais e registrais para a aquisição de imóveis rurais por estrangeiros demonstram a sua complexa normatização, que inclui a falta de observância dessas disposições pelo notário ou pelo registrador, o que resulta na nulidade de pleno direito do ato de transmissão do bem imóvel em apreço, bem como na punição do oficial que pode sofrer as sanções previstas em lei e nas normas da corregedoria de seu Estado.

Um problema adicional refere-se ao papel das tradings internacionais, que controlam a produção de grãos no Brasil e se apropriam de grandes glebas de terras para a implantação de projetos de larga escala de plantações, agropecuária, madeireiras, mineração, turismo, hidrelétricas, produção de alimentos para exportação; numa rede de negócios que se estende 
também, aos países da África, Ásia, e toda a América Latina, numa velocidade de alianças imperiosas, cuja cédula de produto rural é o instrumento desse controle. A apropriação de terras e do controle efetivo da produção de grãos por conglomerados multinacionais, numa perspectiva realista, direciona o leitor a uma reflexão crítica do art. 190 da Constituição; e da interdependência econômica (WALTZ, 1986, p. 101).

A análise mostra que aqueles que vivem da agricultura se especializam nesta função, o industrial depende dos que plantam para comer; os que plantam dependem dos industriais para adquirirem suas máquinas, num ciclo capitalista. Por exemplo, o Japão possui poucos recursos minerais, por isso depende de outros países para adquirir estes recursos. Em contrapartida, o Brasil oferece terras, mão-de-obra barata, criando assim uma rede de conexões que surgiu em face da desigualdade de capacidade entre as nações.

Para se alcançar os possíveis resultados nesse trabalho, apresenta-se um estudo descritivo-analítico desenvolvido através de pesquisa bibliográfica, que se enquadra nos campos de Direito e Desenvolvimento, assim como no Direito e Economia, visando à análise das regras vigentes que limitam a aquisição de imóveis rurais por estrangeiros. Do ponto de vista sociológico, questionam-se os problemas que podem resultar em caso da aquisição de considerada parte do território brasileiro por pessoas de outros países.

Trabalha-se com a ideia de que se deve combater o capitalismo exacerbado, a imposição dos investidores estrangeiros, a fim de se manter as tradições culturais, a união das populações locais economicamente vulneráveis, indígenas, ribeirinhos, quilombolas, pescadores, artesãos, preocupados com a preservação de suas culturas, e do meio ambiente sustentável.

\section{A GLOBALIZAÇÃO E O PROBLEMA DE ACESSO ÀS TERRAS BRASILEIRAS POR ESTRANGEIROS}

O capitalismo trouxe a Divisão Internacional do Trabalho (DIT). Na primeira fase da DIT primeiras décadas do século XX - existia uma forte dependência dos países periféricos da exportação de monoculturas que trazia as riquezas que possibilitavam a importação de bens manufaturados dos países mais desenvolvidos (POCHMANN, 2009, p. 47).

Com o fim da Segunda Guerra Mundial houve uma bipolarização nas relações internacionais entre União Soviética e Estados Unidos (Guerra Fria). Apesar das divergências, a URSS concluiu que precisava de paz, de ajuda econômica e do assentimento diplomático de 
seus antigos aliados. Gaddis (2006, p. 12) doutrina que a escolha recaiu na busca por cooperação de americanos e ingleses. Stalin, influenciado pela ideologia marxista-leninista, acreditava que os capitalistas nunca seriam capazes de cooperar entre si por muito tempo, uma vez a ganância era inerente ao capitalismo, percebia-se uma irresistível necessidade de por o lucro acima da politica. Gaddis (2006, p. 13) infere que a ideia de uma crise interna do capitalismo era até certo ponto plausível, uma vez que a Primeira Guerra Mundial fora uma guerra entre capitalistas.

Mas, o que se verificou foi que os diversos estados nacionais estabeleceram relações multilaterais por meio de organizações não estatais (ONU, FMI, BIRD, GATT). Essa interferência externa alterou a noção moderna da soberania estatal. Nesse contexto, algumas nações não desenvolvidas, antes dependentes somente da exportação de bens primários e importação de produtos manufaturados, conseguiram atingir graus satisfatórios de industrialização. Os governos desses estados periféricos tiveram papéis relevantes já que garantiram as condições necessárias para que os seus mercados internos se expandissem, e, concomitantemente, continuassem protegidos contra agentes econômicos externos (POCHMANN, 2009, p. 48).

O Brasil foi um desses países que conseguiu deixar a dependência somente da exportação de produtos primários para atingir um padrão de industrialização, especialmente, nas regiões Sul e Sudeste. A despeito desse relativo desenvolvimento industrial, o país tem uma aptidão natural ao desenvolvimento agrícola, em razão da sua dimensão territorial e a qualidade do seu solo. Com efeito, a produção agrícola é ainda relevante para a balança comercial $^{3}$.

A partir do final da década de 1970, abre-se a terceira fase da Divisão Internacional do Trabalho, baseado em duas vertentes impostas pelo capitalismo: a reestruturação dos conglomerados empresariais que em forma de oligopólio passam a dominar os mercados mundiais e os Investimentos Diretos no Exterior (IDE), que são importantes para o desenvolvimento dos mercados dos países periféricos (POCHMANN, 2009, p. 49).

Os investimentos em países de terceiro mundo se dão por três motivos básicos: quando há abundância de recursos naturais, os mercados locais são interessantes, e se há condições vantajosas de operação. Nos últimos anos, essas razões tradicionais foram completadas por fatores ligados à intensificação da globalização econômica (SORENSEN, 2010, p. 69).

\footnotetext{
${ }^{3}$ Ver notícia do Ministério da Economia e Emprego sobre o superávit da balança comercial no ano de 2016. Disponível em <http://www.brasil.gov.br/economia-e-emprego/2016/08/balanca-comercial-temsuperavit-de-us-30-bi-em-2016> Acesso em 15 maio 2017.
} 
As corporações multinacionais estão preocupadas em expandir seus negócios aumentando os seus ganhos (DENNY; JULIÃO, 2017, p. 212), principalmente, em razão das facilidades de transações estabelecida pela globalização. As empresas transnacionais, no estado pós-moderno, desenvolvem relações complexas com os estados. As suas estratégias, de escala global, tendem a criar sua própria regulação desconsiderando as limitações impostas pelos estados. Por outro lado, são dependentes de regras internacionais estáveis para que possam executar os seus planos com segurança jurídica. Assim, as relações entre multinacionais e estados são relevantes para os dois lados: as empresas precisam do suporte estatal para se estabelecer e os estados necessitam daquelas para garantir a industrialização, o equilíbrio do mercado e a preservação dos empregos (FRANCO, TABAK, BIJOS, 2017, p. 355). No mundo globalizado, os aspectos políticos e econômicos estão ligados de forma imbricada (CHEVALLIER, 2009, pp. 48-49).

Questão chave é saber se esses investimentos estrangeiros trazem desenvolvimento para os países periféricos. Gilpin (2004, p. 220) enfatiza que essas inúmeras firmas gigantescas instalam-se nos mais remotos locais do mundo, expandem seus negócios e transformam em hábitos o uso de seus produtos, mas se tornam uma séria ameaça para o bem-estar social e econômico dos trabalhadores, das pequenas empresas e das comunidades locais do país. Ao instalarem seus negócios no exterior, elas estarão privando os seus compatriotas de empregos, aviltando os salários e destruindo comunidades que antes eram saudáveis.

Essas empresas não desenvolvem as capacidades de seus trabalhadores, não colaboram com o desenvolvimento local, somente remetem os lucros para suas matrizes. Se essas capacidades forem baixas as empresas controlam o mercado, pagam salários baixos e repatriam os lucros. Se as capacidades forem altas as empresas locais se beneficiam no que se refere às transferências tecnológicas, ao acesso aos mercados, à melhora da qualidade dos produtos e ao desenvolvimento da competitividade. Em relação, especificamente, à capacidade política, o estado que recebe os investimentos externos precisa criar um marco regulatório ótimo para que esses investimentos continuem chegando (SORENSEN, 2010, p. 69-70).

A análise em questão se volta para o malefício dessa corporações multinacionais que tentam convencer seus dirigentes e os cidadãos de outros países onde se instalam de que efetivamente aumentam as exportações, os empregos e os salários. E o que pensam os países receptores de investimentos diretos estrangeiros? Se de um lado dão-se conta de que o investimento direto estrangeiro (IDE) aporta capital e tecnologias valiosas ao país, do outro lado podem ser dominadas e exploradas por essas poderosas empresas. 
Que regras jurídicas internacionais devem ser regulamentadas para assegurar que funcionários e governos tenham seus direitos resguardados?

Nesse contexto de mundo globalizado, a aquisição de terras por estrangeiros no Brasil é, ao mesmo tempo, uma necessidade de grandes corporações multinacionais que estão privadas de terras agricultáveis em seus países de origem, seja por limitação econômica, seja por restrição de disponibilidade, e, também, um problema de política pública uma vez que o excesso de terras em mãos estrangeiras pode resultar tanto em risco à soberania nacional, quanto em maior desigualdade social, já que dificulta o acesso às terras brasileiras aos produtores nacionais, especialmente, aos pequenos agricultores, em razão da natural elevação dos preços dos imóveis rurais. A questão se fundamenta de um lado na teoria da nacionalidade, elaborada por P. Stanislaw Mancini (MELLO, 2004, p. 148), que sustenta que "a nação é uma sociedade natural de homens, como unidade de território, de origem, de costumes e de língua com uma consciência social e vida em comum"; o que demanda a proteção das terras e de seus cidadãos. Daí a necessidade da regulação e da limitação do acesso às terras nacionais por pessoas estrangeiras.

\section{A REGULAÇÃO BRASILEIRA E O LAND GRABBING}

A lei no 5.709/71 regulou no Brasil os limites e os requisitos para a aquisição de imóveis rurais por estrangeiros. Referida lei, editada ainda no começo da ditadura militar, foi promulgada com o fim de controlar e limitar a aquisição de terras por pessoas físicas não brasileiras com residência no Brasil, bem como por pessoas jurídicas estrangeiras ou empresas nacionais controladas por pessoas estrangeiras residentes ou com sede no estrangeiro. Essa legislação contribuiu decisivamente para o retardamento do fenômeno do land grabbing apropriação de glebas de dimensões continentais, a partir de 100 mil hectares (Sociedade Rural Brasileira; Folha de São Paulo, 17.09.2017).

Entretanto, em razão de falhas na devida fiscalização do Instituto de Colonização e Reforma Agrária - INCRA (2017), bem como da desídia de vários cartórios de registro de imóveis por esse país, que deixaram, ao longo dos anos, de atender o comando do art. 11 da lei no 5.709/71, que exige a comunicação trimestral, àquela autarquia federal e à Corregedoria de Justiça do respectivo Estado, dos imóveis rurais adquiridos por estrangeiros no período, o controle dessas aquisições não foram efetivados de forma satisfatória. 
O Sistema Nacional de Cadastro Rural (SNCR), em razão de deficiências claras, não espelham a realidade de terras sob controle de estrangeiros no Brasil. Sauer (2010, p. 80) aponta a existência de reportagens por jornais brasileiros que demonstram que várias dessas aquisições não são registradas no SNCR, culminando em um processo de "estrangeirizacao" das terras no Brasil. Tamanha é a importância do tema debatido no presente artigo, que o art. 190 da Constituição Federal de 1988 previu, expressamente, a regulação por lei de aquisição e arrendamento de terras por estrangeiros. Insta colacionar esse dispositivo constitucional:

Art. 190. A lei regulará e limitará a aquisição ou o arrendamento de propriedade rural por pessoa física ou jurídica estrangeira e estabelecerá os casos que dependerão de autorização do Congresso Nacional.

Nesse diapasão e em consonância com o dispositivo constitucional retro citado, o art. 23 da Lei 8.629/93 estendeu ao arrendamento rural por estrangeiro as disposições da lei no 5.709/71. Releva ressaltar que a lei no 5.709/71 regula a aquisição e arrendamento (lei no 8.629/93) de imóveis rurais por estrangeiros, nada dispondo sobre imóveis urbanos. De sorte que não há qualquer restrição para a citada aquisição de imóveis que estejam no perímetro urbano das cidades. Essa questão é curial para o registro de imóveis, uma vez que, tratando-se de imóveis urbanos, valem as regras de aquisição comum, não estando os registradores de imóveis obrigados a observar as prescrições da lei ora em apreço. Todas as pessoas físicas que não forem brasileiras estão sujeitas às prescrições da lei no 5.709/71. O conceito de estrangeiro é estabelecido por exclusão, ou seja, caso a pessoa física não seja brasileira, nata ou naturalizada, nos termos do art. 12 da Constituição Federal, deve ser considerada estrangeira, e, destarte, deve observar as normas da lei no 5.709/71 para a aquisição ou arrendamento de terras no Brasil.

Somente os estrangeiros com residência no Brasil podem adquirir ou arrendar imóveis rurais no país. Residência não se confunde com o domicílio. Segundo o art. 70 do Código Civil "o domicílio da pessoa natural é o lugar onde ela estabelece a sua residência com ânimo definitivo". A pessoa pode residir em vários lugares diferentes, mas o seu domicílio é o lugar onde se presume que, habitualmente, se encontre e realize os seus atos e negócios jurídicos (DINIZ, 2010, p. 119). Assim, para os efeitos da lei de aquisição de terras por estrangeiros, basta a residência do estrangeiro no Brasil, não necessitando que o seu domicílio habitual esteja em território brasileiro.

Assim, as pessoas físicas estrangeiras poderão adquirir imóveis de até três módulos de exploração sem a necessidade de autorização do INCRA (art. 70, §1으 do Decreto 74.695/74). Mesmo, nesse caso, os demais requisitos previstos na lei em comento deverão ser cumpridos 
sob pena de nulidade do ato de transmissão. O módulo de exploração indefinido (MEI) é fixado pelo INCRA, de acordo com critérios definidos em regulamento, para cada região específica do território nacional.

A aquisição em tela entre três e cinquenta MEl depende de autorização específica do INCRA para a lavratura da escritura de transmissão do imóvel, bem como para o seu registro no cartório competente. Independente do tamanho do imóvel, caso esse se encontre em área de segurança nacional, além da autorização do INCRA, é necessária a autorização do Conselho de Defesa Nacional (art. 7oㅡ, da lei no 5.709/71). Em caso de aquisição ou arrendamento de área superior a cinquenta MEl, é obrigatório, ainda, a autorização do Congresso Nacional (art. 23, $\S 2$ o da lei no 8.629/93).

\section{AQUISIÇÃO DE IMÓVEIS RURAIS POR PESSOAS FÍSICAS ESTRANGEIRAS}

Somente os estrangeiros com residência no Brasil podem adquirir ou arrendar imóveis rurais no país. Residência não se confunde com o domicílio. Segundo o art. 70 do Código Civil "o domicílio da pessoa natural é o lugar onde ela estabelece a sua residência com ânimo definitivo". A pessoa pode residir em vários lugares diferentes, mas o seu domicílio é o lugar onde se presume que, habitualmente, se encontre e realize os seus atos e negócios jurídicos (DINIZ, 2010, p. 119). Assim, para os efeitos da lei de aquisição de terras por estrangeiros, basta a residência do estrangeiro no Brasil, não necessitando que o seu domicílio habitual esteja em território brasileiro.

Assim, as pessoas físicas estrangeiras poderão adquirir imóveis de até três módulos de exploração sem a necessidade de autorização do INCRA (art. 70, §1으 do Decreto 74.695/74). Mesmo, nesse caso, os demais requisitos previstos na lei em comento deverão ser cumpridos sob pena de nulidade do ato de transmissão. O módulo de exploração indefinido (MEI) é fixado pelo INCRA, de acordo com critérios definidos em regulamento, para cada região específica do território nacional.

A aquisição em tela entre três e cinquenta MEl depende de autorização específica do INCRA para a lavratura da escritura de transmissão do imóvel, bem como para o seu registro no cartório competente. Independente do tamanho do imóvel, caso esse se encontre em área de segurança nacional, além da autorização do INCRA, é necessária a autorização do Conselho de Defesa Nacional (art. 7o, da lei no 5.709/71). Em caso de aquisição ou arrendamento de área 
superior a cinquenta MEl, é obrigatório, ainda, a autorização do Congresso Nacional (art. 23, $\S 2$ da lei no 8.629/93).

Nesse caso, deve prevalecer as restrições da lei, exigindo-se a anuência dos órgãos responsáveis, sob risco da possibilidade de fraudes em aquisição de terras rurais por pessoas interpostas. Isso porque em uma possível separação do casal, o bem poderia restar para o cônjuge estrangeiro. Essa prática poderia se tornar corriqueira, em total afronta ao disposto em lei. Problema que não pode ser resolvido em controle prévio pelo cartório de registro de imóveis, é o caso de brasileiro, proprietário de imóvel rural, casar-se com estrangeira e o regime de bens do casamento resultar em comunicação dos bens. Nesse caso, quando for averbado o casamento na matrícula do imóvel, o Oficial deve remeter a comunicação desse ato para os órgãos oficiais, em atenção ao art. 11, da lei no 5.709/71.

No caso da pessoa de nacionalidade portuguesa que, com base no estatuto da igualdade (Decreto n. 3.927/2001), adquirir igualdade de direitos aos brasileiros (art. 12, II, §1응 da (F) por decisão do Ministro da Justiça, não é necessária a autorização para aquisição de terras no Brasil, valendo as regras comuns de aquisição de terras rurais como se brasileiros fossem.

Por último, em razão do disposto no $§ 3$ 으, do art. 1 을 da lei no 5.709/71, fica excluído os efeitos dessa lei em relação à sucessão legítima. Assim, não há qualquer óbice ao registrador de imóveis em registrar o formal de partilha em favor de herdeiro estrangeiro sem autorização dos órgãos acima citados.

O primeiro ponto a ser observado em relação à aquisição de terras por pessoas jurídicas estrangeiras é a existência de autorização para funcionar no Brasil. Sem essa autorização, não é possível a aquisição. A competência para a autorização é do Poder Executivo federal nos termos do art. 1.213, § único do Código Civil.

Os limites para aquisição são os mesmos das pessoas físicas, ou seja, até cinquenta MEI é necessária a autorização do INCRA, e, acima desse montante, somente por autorização do Congresso Nacional. Insta esclarecer que as pessoas jurídicas estrangeiras, independente do tamanho da área, só poderão adquirir imóveis rurais destinados à implantação de projeto agrícola, pecuário, industrial, ou de colonização, vinculados aos seus objetivos estatutários (art. 11 do Decreto no 74.965/74), desde que aprovado pelo INCRA. Assim, para as pessoas jurídicas, mesmo em áreas inferiores a três $\mathrm{MEI}$, é essencial a autorização desse órgão para regular transmissão do bem imóvel rural. 
Disposição que gerou várias controvérsias, após o advento da Constituição de 1988, é a do $\S 1$, , do art. 1 을 da lei ํo 5.709/71 que estabelece que a lei deve ser aplicada, também, às pessoas jurídicas nacionais que sejam controladas por pessoas físicas estrangeiras ou jurídicas que tenham sede no exterior.

Até o início da vigência da Constituição de 1988 não havia nenhuma restrição à aplicação da lei no 5.709/71 nesses casos. Entretanto, o Parecer no GQ - 181 da Advocacia-Geral da União, de 1998, que acatou o Parecer no AGU/LA-04/94, também, da Advocacia Geral da União, entendeu que o parágrafo único do art. 1o da Lei n. 5.709/71 não havia sido recepcionado pela Carta Magna. Isso porque a redação original do art. 171 da Constituição considerava empresa brasileira aquela constituída pelas leis brasileiras desde que tivesse sede e administração no Brasil, independente da nacionalidade dos seus sócios.

Em 2010, a Advocacia Geral da União reviu o parecer anterior, através do Parecer LA n. 01-2010, de 23 de agosto de 2010, que confirmou o parecer CGU/AGU no 01/2008-RVJ, entendendo que, na verdade, o parágrafo primeiro em apreço foi recepcionado pela Constituição de 1988. Assim, novamente, as empresas nacionais controladas por pessoas estrangeiras ou com sede no estrangeiro estariam sujeitas as prescrições da Lei n. 5.709/71.

É interessante notar, que a mudança de posicionamento da AGU, está muito mais ligada à preocupação do governo federal em relação à possível excesso de aquisição de terras por estrangeiros que detenham o controle de empresas nacionais, do que com a questão jurídica sobre a recepção ou não do dispositivo acima citado. É notório que a repristinação não é aceita dentro do ordenamento jurídico brasileiro. De sorte que uma vez não recepcionado dispositivo legal, somente através da edição de nova lei é que seria possível a sua incidência.

A proposta de alteração do parecer adveio da Casa Civil da Presidência da República, em face da preocupação com o efetivo controle desses imóveis rurais, que estavam em poder de pessoas, físicas ou jurídicas, estrangeiras. O fato é que a partir do novo entendimento da AGU, os cartórios de registros de imóveis brasileiros voltaram a exigir autorização do INCRA, em caso de aquisição de imóvel rural por empresa brasileira, sob controle de estrangeiros.

Os aspectos notariais e registrais seguem regras específicas que serão especificadas no próximo tópico. 


\section{ASPECTOS NOTARIAIS E REGISTRAIS}

Os aspectos notariais e registrais seguem as especificações jurídicas, como no caso do brasileiro casado com estrangeira cujo regime de bens prevê a comunicação dos bens do casal.

Ocorre que essa sistemática da lei № 5.709/71 não inibe, efetivamente, essa forma de aquisição. A burla ao sistema é realizada com facilidade. Basta que o imóvel seja adquirido por pessoa jurídica brasileira, com controle de brasileiros, e, posteriormente, as suas cotas ou ações serem cedidas para estrangeiros. A grande questão é que não há como o cartório controlar as cessões de cotas de pessoas jurídicas, visto que não há na legislação dos registros públicos a obrigatoriedade da averbação de toda e qualquer alteração do contrato social ou do estatuto da empresa. Somente as alterações que, de alguma forma, tenham o condão de alterar a especialidade subjetiva da matrícula, é que têm acesso ao fólio real.

A AGU recomendou ao Ministério do Desenvolvimento, Indústria e Comércio a edição de regulamento proibindo o registro do controle acionário de empresas em nome de pessoas estrangeiras, residentes ou com sede no exterior, que detenham imóveis rurais. Entretanto, esta recomendação é inócua já que, normalmente, a propriedade do imóvel não aparece no contrato social. Não há como se controlar a disponibilidade da terra pela alteração do contrato social.

Uma solução paliativa seria a edição de uma lei obrigando as juntas comerciais, como obrigam os cartórios, a oficiarem ao INCRA a ocorrência do registro de alterações de contratos sociais ou estatutos, em que o controle da empresa passe para as mãos de pessoas estrangeiras. Mesmo assim, esse controle não seria seguro, haja vista que, salvo os casos de incorporação de imóvel ao capital social, não há como aferir-se se a empresa é proprietária de bens rurais imóveis a partir das citadas alterações. Outra solução, também, paliativa, seria obrigar a Receita Federal oficiar ao INCRA a transferência do controle para estrangeiros. Mas, resultaria no mesmo problema das juntas comerciais, uma vez que nas declarações das pessoas jurídicas a esse órgão não há campo específico para a indicação de cada um dos bens imóveis de sua propriedade.

O fato é que se torna realmente, difícil o controle efetivo de quais empresas nacionais são proprietárias de imóveis rurais.

Em razão do Parecer LA n. 01-2010 da AGU, o Conselho Nacional de Justiça, preocupado com o descontrole das terras adquiridas por pessoas jurídicas nacionais sob controle de estrangeiros, no Pedido de Providências no 0002981-80.2010.2.00.0000, resolveu recomendar 
as Corregedorias de Justiça dos Tribunais de Justiça dos Estados que determinassem aos cartórios de registro de imóveis e aos tabelionatos de notas, a

observância rigorosa das disposições da lei no 5.709/71, na lavratura de escrituras de compra e venda ou do registro dessas, quando o comprador for pessoa jurídica nacional controlada por estrangeiros. Posteriormente, nos mesmos termos da decisão acima, o Conselho Nacional de Justiça editou o Provimento no 43, de 17/04/2015, exigindo dos cartórios de registro de imóveis e dos tabelionatos de notas a observância da lei no 5.709/71 em relação aos arrendamentos de imóveis rurais por estrangeiro, bem como por pessoa jurídica nacional controlada por estrangeiros.

A lei no 5.709/71 limitou a aquisição de imóveis rurais por estrangeiros e empresas nacionais controladas por estrangeiros em 25\% (vinte e cinco por cento) da superfície do município. Igualmente, limitou em 10\% (dez por cento) da citada superfície a aquisição por pessoas de uma mesma nacionalidade. Essas limitações são essenciais para o combate ao land grabbing, que vem ocorrendo ao longo do mundo, principalmente, na África e na América Latina. Segundo Sauer (2010, p. 78), a demanda por terras em outros países cresceu exponencialmente após o ano de 2008:

Segundo estudo do Banco Mundial (2010), a demanda mundial por terras tem sido enorme, especialmente a partir de 2008, tornando a "disputa territorial", histórica no Brasil e na América Latina, um fenômeno global. Segundo este estudo, comparativamente, a transferência de terras agricultáveis (ou terras cultivadas) era da ordem de quatro (04) milhões de hectares por ano antes de 2008. Só em 2009, mais precisamente entre outubro de 2008 e agosto de 2009, foram comercializadas mais de 45 milhões de hectares, sendo que $75 \%$ destes foram na África (BANCO, 2010, p. vi).

Vários países da América Latina não possuem lei coibindo ou limitando a aquisição por estrangeiros de imóveis rurais. O debate ganhou maior relevo, já que houve elevação substancial dos preços dos alimentos na última década. O agravamento de crises mundiais, também, reflete diretamente no campo, visto que é nesse meio que a pobreza é encontrada com maior frequência (SILVA, 2013, p. 3).

A legislação brasileira, em vigor há algumas décadas, é interessante para o Brasil, principalmente, porque vem combatendo a comercialização de extensas glebas de terras agricultáveis por estrangeiros. Entretanto, conforme acima assinalado, a tarefa de fiscalizar, efetivamente, a quantidade de terras em mãos de estrangeiros não é nada fácil, mesmo com a vigência dessa lei há tanto tempo. 
Há algumas exclusões de áreas em mãos de estrangeiros para o cômputo da superfície do município que é importante assinalar. Segundo o art. 12, §2º, ficam excluídas das restrições as aquisições por estrangeiros dos seguintes imóveis:

I. inferiores a 3 (três) módulos;

II. que tiverem sido objeto de compra e venda, de promessa de compra e venda, de cessão ou de promessa de cessão, mediante escritura pública ou instrumento particular devidamente protocolado no Registro competente, e que tiverem sido cadastradas no INCRA em nome do promitente comprador, antes de 10 de março de 1969;

III. quando o adquirente tiver filho brasileiro ou for casado com pessoa brasileira sob o regime de comunhão de bens.

Nos casos acima especificados, o legislador optou por não levar em consideração para o cômputo da superfície do município de imóveis nessas condições. É uma opção legislativa, mas, também, pode ser um problema, uma vez que há a possibilidade de imóveis rurais do município estar, em sua maioria, nas mãos de estrangeiros.

Outra crítica à lei no 5.709/71, é que existem municípios brasileiros, principalmente, no norte do país, que são maiores do que países europeus. Assim, um quarto de sua área seria maior do que a superfície de um país inteiro. De qualquer sorte, a lei em tela foi um passo importante para a restrição da apropriação de terras. Juridicamente esses dispositivos podem ser aperfeiçoados, mas, a sua existência vem coibindo, de certa forma, essa modalidade de aquisição.

Igualmente, a aquisição sem a observância de suas disposições, resulta em nulidade absoluta. É uma forma de controle por parte do Estado, que apesar de não ser prévio, é eficiente porque é um bom e rápido instrumento para o reconhecimento da nulidade dessas transações junto ao Poder Judiciário (art. 214 da lei no 6.015/73).

O grande mérito da sistemática imposta pela lei no 5.709/71, é a previsão de nulidade absoluta da transmissão de imóveis rurais a estrangeiros, sem a observância de qualquer de suas disposições. Insta colacionar o seu art. 15:

Art. 15 - A aquisição de imóvel rural, que viole as prescrições desta Lei, é nula de pleno direito. O tabelião que lavrar a escritura e o oficial de registro que a transcrever responderão civilmente pelos danos que causarem aos contratantes, sem prejuízo da responsabilidade criminal por prevaricação ou falsidade ideológica. O alienante está obrigado a restituir ao adquirente o preço do imóvel.

Independente da responsabilidade imposta ao alienante de devolver o preço recebido pela alienação do imóvel, previsto do final desse artigo, a transmissão, sem o cumprimento dos requisitos impostos pela lei, é nula de pleno direito. 
Assim, uma vez anulado o ato, via processo judicial, cabe ao estrangeiro adquirente propor ação de reparação de danos em desfavor do alienante para receber o montante pago pelo imóvel.

A nulidade da aquisição pode ser requerida pelos interessados diretos em ação individual, bem como através de ação civil pública ou ação popular, propostas pelos legitimados constitucionalmente.

Há, também, a responsabilidade civil e criminal do tabelião que lavra a escritura e do registrador de imóveis que registra a transmissão, sem o cumprimento da legislação. 0 prejudicado, uma vez provado o dano resultante do ato ilegal praticado pelo oficial do cartório, tem direito a indenização pelos prejuízos sofridos.

De mais a mais, o oficial ainda pode sofrer sanções administrativas, podendo culminar na perda da delegação, dependendo das circunstâncias do caso e da reiteração de erros cometidos nessas aquisições sem a observância dessa lei.

O art. 8o da Lei no. 5.709/71 exige a escritura pública para a aquisição de terras por estrangeiros. Esta disposição é uma exceção ao art. 108 do atual Código Civil, que somente exige escritura pública para alienação de bem imóvel quando seu valor superar o correspondente a trinta salários mínimos.

Na verdade, a Lei no 5.709/71 é um micro sistema próprio que regula especificamente a aquisição de terras por estrangeiros. Dessa sorte, é lei especial que não pode ser derrogada por lei geral, como é o caso da previsão do art. 108 do Código Civil

O legislador exigiu a escritura pública para todos os casos visando uma maior segurança jurídica, principalmente, em relação ao controle dessas aquisições por estrangeiro. É que o tabelião é obrigado a fazer constar no bojo da escritura a autorização emitida pelo INCRA autorizando a venda a estrangeiro (art. 9o, III da Lei n. 5.709/71 e art. 10, III do Decreto n. 74.965/74).

Caso não houvesse esta exigência, certamente, vários imóveis seriam comercializados através de documentos particulares, que não teriam acesso ao registro de imóveis por falta de autorização do INCRA. Dessa sorte, a exigibilidade da escritura pública acaba resultando em uma maior garantia ao estrangeiro, e, ao mesmo tempo, é um instrumento para o controle de aquisições de imóveis rurais por estrangeiros, já que o tabelião está proibido de elaborá-la sem a presença da referida autorização. 


\section{CONSIDERAÇÕES FINAIS}

Os possíveis resultados na investigação da aquisição de terras brasileiras por parte corporações multinacionais visam resguardar as faixas de fronteira, que são indispensáveis à segurança nacional; além da autorização específica do INCRA, e a autorização do Conselho de Defesa Nacional.

Importante ressaltar o papel dos cartórios de registros de imóveis, na pessoa do notário e do registrador, que devem agir em conformidade com as normas da corregedoria de seu Estado especifico.

Problemas como o caso de usucapião de imóvel rural por estrangeiro, a melhor interpretação é a de que o juízo deve exigir a autorização do INCRA antes de expedir o mandado ao registro de imóveis. É que não há hipótese, dentro do sistema da Lei no. 5.709/71, de dispensa de exigência dessa autorização. Caso o mandado seja apresentado no registro de imóveis, desacompanhado da referida autorização, o registrador de imóveis deve emitir nota devolutiva, exigindo a sua apresentação para que o registro seja efetuado.

Outro ponto pertinente é a aquisição de imóvel rural por fundo imobiliário. É que esses fundos não possuem personalidade jurídica. Os bens são adquiridos pela instituição administradora, em caráter fiduciário, nos termos do art. 6o da lei ํo 8.668/93. Os reais proprietários são os seus quotistas. A administradora, apesar de aparecer no ato como proprietária atua como fiduciária. Nesse caso, se a maioria dos quotistas for de nacionalidade estrangeira, são necessárias as autorizações do INCRA e do Conselho de Defesa Nacional. De posse desses requisitos formais como a menção na escritura pública do documento de identidade do adquirente e prova de residência no território nacional (art. 9o da lei no 5.709/71), que, não necessariamente, resultam em nulidade absoluta do ato. Isso porque, caso o comprador estrangeiro seja acionado, é possível que esse demonstre em juízo que detinha a identidade de estrangeiro regularizada e residia no Brasil, à época da transmissão. Os cartórios de registro de imóveis e os tabeliães de notas exercem, na verdade, um controle prévio da aquisição de terras por estrangeiros. É, assim, mais um munus público atribuído aos mesmos por lei.

Outra obrigação dos cartórios de registro de imóveis é manter um livro especial de aquisição de imóveis rurais por estrangeiros (art. 10 da lei no 5.709/71). Esse livro é importante para conhecimento do número de imóveis e da quantidade de terras que são de propriedade de estrangeiros no município. Através dos registros constantes nesse livro, bem como do 
controle efetivado pelo INCRA, será possível saber com precisão qual a porcentagem da área do município está em mãos de estrangeiros e quais as nacionalidades dos seus proprietários. 0 controle de quantidade de áreas máximas de propriedades rurais de estrangeiros, previsto no art. 12 dessa lei, será, facilmente, aferível por meio da confrontação dos dados desse livro com a quantidade total de imóveis rurais pertencentes ao município constantes dos registros gerais do cartório.

É de suma importância que se fiscalize os contratos firmados entre as tradings internacionais e os produtores rurais, garantidos por cédulas de produto rural (CPR), regulamentada pela lei no 8.929/94. Através da CPR, as tradings financiam o produtor rural para que esse entregue sua produção, ou parte dela, em uma data determinada. A garantia da entrega é real, consubstanciada através de hipoteca, penhor ou alienação fiduciária.

A formação de oligopólio por essas empresas e a atuação em larga escala, deixa os produtores rurais cada vez mais dependentes desses financiamentos. O poder de negociação dos produtores diminui, resultando em contratos menos interessantes para os mesmos. 0 maior problema é que essas empresas atuam em conjunto, elaborando um cadastro único dos produtores rurais, estudando a sua capacidade de endividamento, as suas áreas cultivadas e negando acesso aos financiamentos, através de uma lista negra dos produtores que contestam os contratos judicialmente ou desviam a produção de forma ilícita.

O poder das tradings internacionais se estende ao monitoramento da safra (área cultivada por sojicultor), à situação econômica do agricultor (se possui dívida, o valor da dívida, as suas condições de pagamento, quais os credores, regularidade do pagamento dos empréstimos, se a certidão das terras não está hipotecada, situação financeira, para que possam manipula-los livremente, coercitivamente.

O fato essencial, para a compreensão de uma politica de poder, é que essas tradings não estão interessadas em adquirir ou arrendar terras. Na verdade, elas controlam grande parte da produção através de financiamentos, garantidos por cédulas de produto rural. É o sistema estabelecido na lei no 8.929/94 que garante a possibilidade irrestrita desse controle sobre a produção, sendo desnecessários a aquisição ou arrendamento de imóveis rurais.

Ora, não há diferença entre controlar a aquisição ou arrendamento de terras por estrangeiros e controlar a produção dessas mesmas terras. $O$ fato é que a destinação da terra e o produto da colheita estão em poder de pessoas estrangeiras. Torna-se premente a criação de controle e limitação sobre a quantidade de terras envolvidas em financiamentos garantidos por cédulas de produto rural, cujos credores sejam empresas estrangeiras ou controladas por 
estrangeiros, seja tão efetivo para inibir o land grabbing quanto as disposições da lei no 5.709/71. Como essas cédulas são registradas nos cartórios de registro de imóveis, essas serventias poderiam informar ao INCRA, assim como ocorre em relação à aquisição por estrangeiros, a relação trimestral de todas as cédulas registradas no período.

De lege ferenda, essa ferramenta proposta garantiria um controle e uma limitação complementar às disposições expressas da lei no 5.709/71.

Os possíveis resultados para o controle de aquisição ou arrendamento de terras respaldam-se na criação de um sistema que permita ao INCRA controlar, efetivamente, qual o percentual da produção está em poder dessas pessoas estrangeiras. E, caso a política pública seja a limitação do controle dessa produção, é curial a edição de lei obrigando os cartórios a informar os registros dessas cédulas, para que o INCRA consiga controlar as porcentagens da produção nacional em mãos dessas tradings.

A mensagem final desta pesquisa é que se deve aprender a olhar além do liberalismo, que o Estado avalie a imposição dos investidores estrangeiros; e que novos lampejos sejam lançados para a preservação das tradições culturais, a estabilidade econômica das populações locais, que se valorizem os povos indígenas que ainda habitam a Região Amazônica, e o litoral brasileiro. Ressalte-se, ademais, o papel dos ribeirinhos, dos quilombolas, dos pescadores e artesãos, preocupados profundamente com a preservação de suas culturas, e do meio ambiente sustentável.

\section{REFERÊNCIAS}

CHEVAlLIER, Jacques. O Estado Pós-Moderno. (Trad. Marçal Justen Filho). Belo Horizonte: Fórum, 2009.

DENNY, Danielle Mendes Thame; JULIÃO, Rodrigo Farias. Sistema Nacional de Comércio Justo e Solidário. São Paulo, SP: Revista de Direito Brasileira, v. 16, n. 7, pp. 211-224, Jan./Abr. 2017.

FRANCO, Cláudia Regina Lovato; TABAK, Benjamin M.; BIJOS, Leila. A Lei n. 14.946, 28 de janeiro de 2013, Lei Bezerra, um nudge para empresários do setor de confecção da indústria paulista cumprirem as leis trabalhistas. São Paulo: Revista de Direito Brasileira, v. 16, no. 7, Jan./Abr. 2017, pp. 346-362.

GADDIS, John Lewis. História da Guerra Fria (tradução de Gleuber Vieira), Rio de Janeiro: Nova Fronteira, 2006.

GILPIN, Robert. O Desafio do Capitalismo global, (tradução de Clóvis Marques), Rio de Janeiro: Editora Record, 2004. 
INCRA - Instituto de Colonização e Reforma Agrária, Manual para Orientação de Aquisição de Imóvel Rural por Estrangeiro. 2017. Disponivel em: http://www.incra.gov.br. Acesso: 20/09/2017.

MELLO, Celso D. de Albuquerque. Curso de Direito Internacional Público. 10 Volume, 15ạ Edição, Rio de Janeiro: Renovar, 2004.

POCHMANN, Marcio. Qual desenvolvimento?: oportunidades e dificuldades do Brasil Contemporâneo. 1ạ. ed. São Paulo: Publisher Brasil, 2009.

SAUER, Sérgio. Demanda Mundial por Terras: "land grabbing" ou oportunidade de negócios no Brasil? In: Revista de Estudos e Pesquisas sobre as Américas, vol. 04, no 1/2010, pp. 72-88.

SILVA, Emilia Jomalinis de Medeiros. A atuação das grandes tradings do agronegócio da soja no avanço da fronteira agrícola na BR-163. VI Simpósio Internacional de Geografia Agrária. VII Simpósio Nacional de Geografia Agrária. 1ạ Jornada de Geografia das Águas. 2013. Disponível: em <http://www.nuclamb.geografia.ufrj.br/publicacoes/arquivos/singa_emilia.pdf > Acesso em 20 de setembro de 2017.

SOCIEDADE RURAL BRASILEIRA. Agronegócio Sustentável. Criticada por Ambientalistas, Venda de Terras para Estrangeiros Volta à Tona. Folha de São Paulo, reportagem do jornalista Marcelo Toledo. 17.09.2017.

WALTZ, Kenneth N. in KEOHANE, Robert O. Neorealism and its critics. New York: Columbia University Press, 1986.

Trabalho enviado em 17 de junho de 2017.

Aceito em 19 de outubro de 2017. 